REFLEXIÓN

Recibido: 24/10/2013

Revisado: 24/11/2013

Aprobado: 20/12/2013

\title{
ERÓTICA, CRÍTICA Y POLÍTICA EN LA ESTÉTICA DEL PENSAR BARROCO
}

\author{
MARIO MADROÑERO MORILLO \\ Doctorando en Antropologías contemporáneas de la Universidad del Cauca. \\ Docente hora cátedra. Universidad de Nariño. \\ Docente tutor Universidad Minuto de Dios.
}

\begin{abstract}
RESUMEN
El siguiente texto pretende esbozar una reflexión sobre la relación entre la erótica, la crítica y la política, presentes en la praxis de la estética del pensar barroco, visible en las propuestas de José Lezama Lima y la relectura del barroco que realiza Guilles Deleuze, principalmente, intentando establecer una pauta dialógica que permita señalar, las particularidades de tal relación en los modos de ser del señor barroco, reflejado en una performance de acontecimientos que permiten proponer en el barroco americano una praxis del logos plural de la razón barroca.
\end{abstract}

Palabras claves: Erótica. Crítica. Política. Estética. Barroco.

\section{ABSTRACT}

The following text aims to outline a reflection on the relationship between the erotic, criticism and politics, present in the practice of thinking baroque aesthetics, visible in the proposals of José Lezama Lima and rereading the Baroque performs Gilles Deleuze, mainly, trying to establish a dialogue that allows point pattern, the specifics of that relationship in the ways of being of Mr. baroque, reflected in a performance of events leading to the American Baroque propose a praxis of the logos baroque plural of reason.

Keywords: Erotica. Criticism. Policy. Aesthetics. Baroque.

La articulación entre erótica-críticapolítica, latente en la exposición estética del pensar barroco, la pluralidad de formas de exposición de tal pensar; implica comprender la articulación desde lo que se podría proponer como una meta esquema heteromórfico de conceptos (Deleuze, 1989: 18), dirigido a cartografiar las redes y rizomas de relaciones de ese modo de pensar, a partir de lo que podría proponerse, en el intervalo de tal exposición, como el continuum y discontinuum de una crítica de la razón barroca, inherente a la manifestación de un logos plural, que rebasa en la moción de sus proposiciones, las nociones que sobre la relación entre sensación y sentido del eros barroco, la analítica y hermenéutica del pensar de la crisis barroca y el poder y la relación de la política barroca, constituirían la concepción de tal exposición y crítica, en 


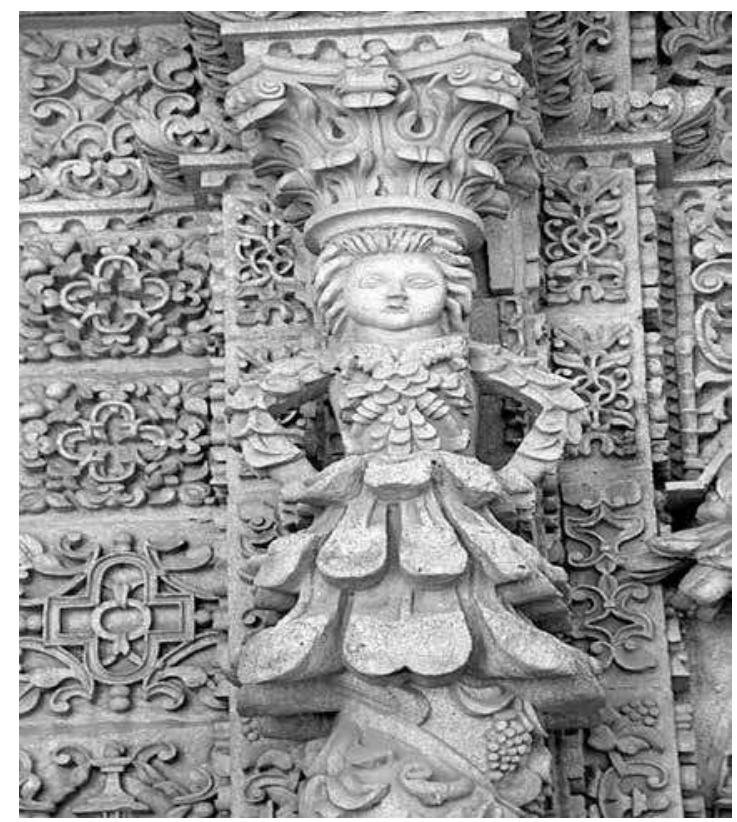

Figura 1

tanto excedentes de una representación, comprendida generalmente desde una comprensión de la razón -las formas de su logos-, infundada en el restringido concepto de cosmovisión.

La restricción cosmovisionaria, provoca una percepción de las relaciones del ser con la naturaleza, por ejemplo, en la que lo mágico en tanto representación de tal relación, se propone como una forma de adhesión mimética acrítica a principios estéticos canónicos, que cierra la posibilidad para la imagen por reducción a lo originario, lo que provoca además un concepto igualmente restringido de arquetipo que reduce la comprensión de lo mágico a una mera fantasía ${ }^{1}$ que descargada de mito (tal como ha expuesto el realismo mágico), estaría privada del aura que la preconcibe y sustenta, tal como refiere Walter Benjamín, la pérdida

1. Fantasía que racionalizada y regulada, pierde el valor de su relación con lo imaginario en tanto expresión del mundus imaginallis, de dónde se presupone (sin ser un lugar fundacional), emergen las formas y figuras de una estética barroca. del aura a la que somete a una obra, el despotismo estético de la reproductibilidad técnica de la obra de arte. En donde los arquetipos clausurados como ídolos, configuran una concepción de fundamento (Grund) en tanto imagen originaria única y cosmovisionaria, que cosifica en sí, la relación del ser con la tierra, el mundo, la naturaleza, los otros, el sentido, los sentidos, la sensación, a partir de una práctica policiva de la representación que pretende controlar la virulencia política de la relación barroca con la vida.

Ante tal inversión nihilista de las relaciones vitales con el cosmos, los ectipos, comprendidos como re-mociones de un imago y un ídolo, por exceso de sentido y sensación, y por tanto expuestos como signos-sensaciones-logos-barrocos de hiper sentidos capaces de intervenciones heurísticas; provocan nuevas dimensiones de y para el sentido, las sensaciones, la estética misma, que se reflejaran en la comunicación, que poética y política; expondría una lengua iconográfica de sentidos diferidos, constituyentes de una gramática de la turbulencia, capaz de decir lo inaudito por lo inacabado de su exposición. De acuerdo con Deleuze:

Una turbulencia nunca se produce sola, su espiral sigue un modo de constitución fractal según el cual nuevas turbulencias se intercalan siempre entre las primeras. La turbulencia se nutre de turbulencias, y en la desaparición del contorno, sólo se termina en espuma o crines. La inflexión misma deviene turbulenta, al mismo tiempo que su variación se abre a la fluctuación, deviene fluctuación. (Ibíd., 28).

Fluxus del sentido, la sensación, la gramática inflexiva de la turbulencia del sentido/sensación, refleja el modo de ser plural de un ethos inacabado por extenso, cuyo perspectivismo crítico, permite ver y trazar lo que de inaudito 
sobrecarga el pensar y que configura una estética crítica, es decir una aisthesis de la apertura del sentido, la sensación, por inacabamiento de obra; no forcluida o aplazada por exigencia técnica o inspiración o genio, sino diferida, es decir en el devenir de la pluralidad de la referencia, cuyo tiempo, expone una repetición del sentido que conjura la obsesión por la comprensión, al saturar la razón y el alma atómicas ${ }^{2}$, llevándola a la multiplicidad de fisión de su indeterminabilidad; lo que provoca una remoción del ser y la emergencia de una ontología intensiva ${ }^{3}$, capaz de materializar espíritus ${ }^{4}$ en la

2. Ver: la noción de "alma atómica" referida por Deleuze en "El pliegue. Leibniz y el barroco". Paidós. Capítulo 2: "Los pliegues del alma". Páginas 25 a 40.

3. Las ontologías intensivas son propuestas por Deleuze y Guattari, los desarrollos de las nociones de ser y extraser, constitutivas de la noción de "superjeto" propuesta por Deleuze y relacionada aquí con la excedencia del "señor barroco" propuesta por Lezama Lima, se relaciona también con la noción de ontología intensiva relacionada con la virtualidad del pensar chamánico sobre el alma multinatural, capaz de ser otro, por ejemplo jaguar, pez, colibrí, piedra, ají desarrolladas por Eduardo Viveiros de Castro en: "Metafísicas Caníbales. Líneas de antropología posestructural". Editorial Katz. 2010. Y de las propuestas de Manuel de Landa, evocadas en su sentido político por Arturo Escobar y Michael Osterweil, en: "Movimientos Sociales y la Política de lo Virtual. Estrategias Deleuzianas". En: Tabula Rasa. No 10. Enero-Junio. 2009. Bogotá. Páginas: 123-161.

4. Como expone José Luis Grosso al referir que se trata de una: "Intercultural counter-narratives break down the minimum possibility of imposing a continued sense in a hermeneutic discourse. Among silence emerges a collective learning of other histories as bodies'histories. Nor hermeneutic neither reflexive, the oblivion makes sense in semiopractical tropes and refractions. The ancestors vanquished by the univocal episteme and ontology and the lives have collectively learned, not at all a new History as a mimetic transposition in logical narrative, but a dislocation of theory from logos to semiopraxis, from reflection to refraction, and from convergent, mono-logical, univocal thinking and ontology to intercultural, cosmic conversation". - Lo que conlleva una invariante que permite proponer la relevancia de la heuristic crítica en la apertura de la clausura del círculo hermenéutico, a partir de la semiopraxis, como contra narrativa, relacionada con la contraconquista del señorío barroco, lo que permite enfatizar con Grosso, que: "This no matter with (re)telling history, but rather with antagonistic counter-narrative senses opening other histories, other relationships, only as well by leaps, by turns iconografía de la semiótica asignificante del logos barroco y su perspectiva, cuyo locus de enunciación dice lo inaudito y cuyo punto de vista da a ver lo invisible, a partir de la hiperfísica ${ }^{5}$ de las relaciones que inaugura con la naturaleza; lo que implica pensar el ser barroco como apertura de sentido de la existencia, en tanto excedente ontológico. Lo que per-

back, by reversing matrixes of creation, by mythical and ritual reconnections, by messianic cadences. In that counter-narratives there is a baroque folding of inside/outside, above/bellow, in front/behind, face/ mask, now/then, dressing/core, surface/strata, that dislocate the usual and naturalized references of space and time." En: Oblivion saves other histories in bodies. Post-colonial semiopraxis, denegation politics, and cultural learnings. 2013. En: VIII Symposium CORPUS Bodily cultivation \& cultural learning. Thematic Area: Memory and Body. Taipei, May 25, 26. Paper. Se añade el subrayado.

5. La hiperfísica es mencionada en relación a la luz, la sombra, la materia, a partir de Aristóteles y el "Tratado del Alma", por George Didi-Hubeman, quien recuerda que: "Aristóteles escribe que el acontecimiento coloreado "existe efectivamente en el límite del cuerpo, pero no es el límite del cuerpo. Hay que pensar más bien que la misma naturaleza que, exteriormente, es el vehículo del color, existe también en el interior del cuerpo". Lo que indica toda la fuerza de confusión, de aura, de evanescencia y de aparición que lleva en sí el colorido. El color en el sentido aristotélico existe por tanto "en el límite", pero existe también, sutil, diferentemente actualizado, tal vez un poco más acá del cuerpo coloreado, tal vez un poco más allá de él, y hasta en mí (el humor acuoso de mi ojo), y más allá de mí. No está depositado en la superficie de los cuerpos, es un juego lábil del límite, un laminado sutil, vacila en todos los aspectos en el espacio, según el aire, según el agua. Es una hiperfísica." En: "La Pintura encarnada". Didi-Huberman, George. (2007) Pretextos. Valencia. Páginas: 33-35. El contexto del comentario hace referencia a la diaphané propuesta por Aristóteles, como la exposición de una imagen, que entre lo visible, la aparición "epíphasis" y lo invisible, la desaparición "aphánisis", se juega en la presencia, su oscilación temporal y por tanto el temblor de la imagen, de la que el gótico podría ser una forma de representación, al igual que el barroco su puesta en límite y por tanto la revolución entre el temblor mismo, que podría referir lo diáfano de la "nueva armonía" evocada por Lezama Lima y Deleuze. En relación al comentario de DidiHuberman, la relación entre "epíphasis" - "aphánisis" - "diaphané" la provoca la "naturaleza mixta (Koinè phýsis)", por ejemplo de una phainestai irregular, relacionada con lo que Deleuze recuerda, a partir de Riezler, citado por André Scala como "un plisado del ser", "un pliegue de lo uno en ser y no-ser que están los dos estrechamente tensados el uno en el otro". En: "El Pliegue. Leibniz y el barroco". Deleuze, Gilles (1989). Paidós. Barcelona. Nota No. 8. Página: 45. 
mite a Deleuze, en relación al punto de manifestación en el que se da el discurrir de tal logos y teoría, referir que:

No es exactamente un punto, sino un lugar, una posición, un sitio, un "foco lineal", línea que surge de líneas. Se le llama punto de vista en la medida en que representa la variación o inflexión. Tal es el fundamento del perspectivismo. Este no significa una dependencia respecto a un sujeto definido previamente: al contrario, será sujeto lo que alcanza el punto de vista, o más bien lo que se instala en el punto de vista. Por eso la transformación del objeto remite a una transformación correlativa del sujeto: el sujeto no es un sub-jeto, sino un "superjeto", como dice Whitehead. (Ibíd., 31). Moción hiperfísica que desde la sobrenaturaleza evocada por Lezama Lima, implicaría, el contrapunteo de la emergencia de un ser barroco, cuya nascencia irrumpiría y corrompería el continuum de la mirada perspectiva del superjeto, desde un señorío barroco ${ }^{6}$ que permite a Lezama, referir, que, si de superjeto en la dimensión de las relaciones barrocas se trata, que tales existencias ectipicas, implicarían un despliegue de sí en otro modo que ser, alterado, cuyas mociones vitales expone como la relación con un ser de otra parte, propuesto como un proto-agonista quien se expone como un:

"Apesadumbrado fantasma de nadas conjeturales", - debido a que - "el nacido dentro de la poesía siente el peso de su irreal, su otra realidad, continuo." -En el punto en el que es capaz de decir lo inaudito, pues- "Su testimonio del no ser, su testigo del acto inocente de nacer,

6. El señorío barroco corresponde a la propuesta de Lezama Lima desarrollada en: "La curiosidad barroca", capítulo 2 de "La expresión americana". FCE. 1993. Páginas: 89 a 119. De igual manera se referirá más adelante la lectura que realiza Juan Duchesne Winter en: "Del príncipe moderno al señor barroco: la república de la amistad en Paradiso, de José Lezama Lima”. Archivos del índice. Cali. 2008. va saltando de la barca a una concepción del mundo como imagen. La imagen como un absoluto, la imagen que se sabe imagen, la imagen como la última de las historias posibles". - Lo que permite una especialización del tiempo, que expone una poética barroca, y por tanto una irregularidad temporal, que en la posibilidad abre la finalidad, por - "El hecho mismo de su aproximación indisoluble," - Visible y audible- "en los textos, de imagen y semejanza," -que- "marca su poder díscolo y cómo quedará siempre como la pregunta del inicio y de la despedida; pues cuanto más nos acerquemos a un objeto o a los recursos intocables del aire, derivaremos con más grotesca precisión que es un imposible, una ruptura sin nemósine de la anterior. Ni es posible que un orgullo desacordado al enarcar la red de la imagen pueda prescindir de la constitución de los cuerpos de donde partió. La semejanza de una imagen y la imagen de una semejanza, unen a la semejanza con la imagen, como el fuego y la fanja de sus colores (Lezama Lima, 1979: 53).

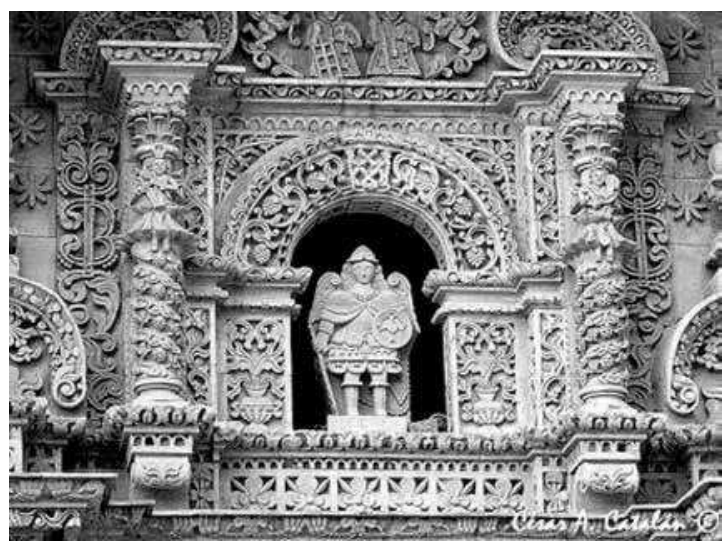

Figura 2

La fluxión imposible entre Lezama y Deleuze, provoca la exposición de una razón barroca que discontinua, provoca la heterocronía de expresión del sentido que abre los pliegues del logos plural del pensar que permite entrever entre los 
intervalos de la exposición de tal precipitación de memoria oceánica e insular, una erótica en tanto logos de la sensación cuya magnitud poética, expresa una política de lo imposible, que trazará las relaciones perspectivistas de la hiperfísica de las relaciones de alteridad con la comunidad imaginal, con un otro mundus imaginallis, en tanto crítica radical a la comprensión genética unitaria del ser cosmovisionario, para expresar una comprensión heterogenética de la poética de la creación, en tanto forma de exposición del tiempo de la creación, que conlleva en el caso de Lezama Lima, pensar en las consecuencias de lo que implica la mención del poeta como "genitor por la imagen" y de Deleuze, cuando al límite del concepto y la puesta en abismo del sentido, propone el "pensar sin imagen", como absolución de la comprensión enciclopédica de la razón filosófica, ante la que el logos del solitario actúa. Acciones que se pueden motivar por las consecuencias de la heurística de la poética barroca, cuyo tiempo espacializado, permite por ejemplo a Lezama Lima (1979), concebir la manifestación de la creación barroca, su poética y política del sentido como "esferaimagen", que a partir de las reflexiones de Deleuze se podría conceptualizar como un geometral, teniendo en cuenta que:

El punto de vista sobre una variación sustituye al centro de una figura o de una configuración. El ejemplo más célebre es el de las cónicas, en las que la punta del cono es el punto de vista al que se refiere el círculo, la elipse, la parábola, la hipérbola, e incluso la recta y el punto, como otras tantas variantes según la inclinación del plano de corte ("escenografías"). Todas esas figuras devienen otras tantas maneras de plegarse un "geometral". Y ese geometral no es exactamente el círculo, que sólo debería tal privilegio a la vieja concepción de la perspectiva, sino el objetil que declina o describe ahora una familia de curvas, las del segundo grado de las que el círculo forma parte. Este objetil, o geometral, es como un despliegue. Pero el despliegue no es lo contrario de lo pliegues, como tampoco la invariante es lo contrario de la variación: es una invariante de transformación. Será designado por un 'signo ambiguo"' (Deleuze, 1989: 32-33).

La esferaimagen por tanto expondrá otro mundus imaginallis paradójico y equivoco, por la ambigüedad de los signos que componen la gramática inflexiva de la turbulencia, de sus sentidos y sensaciones, provocando una concepción total del acontecer que provoca la obra barroca, al saturar de sentido la comprensión llevando el sentido mismo y las sensaciones al límite del entendimiento, excediendo la entelequia, por la magnitud de la remoción de sentido y sensación que conmueve la razón. De igual manera la esferaimagen representaría en esta dimensión crítica, la locomoción de una mónada capaz de mutar tiempos y espacios debido a la "invariante de transformación" que la constituye y que permite exponer la paradoja crítica de la equivocidad del signo ambiguo, que entre lo diáfano y lo misterioso, traza sentidos que compondrían un campo de presentación de la obra barroca en el claroscuro del logos plural, legible en el templum del sentido o el "fuscum subnigrum" de la sensación, ambos componentes de lo que Deleuze propone como la "anamorfosis barroca" (Deleuze, 1989), presente por ejemplo en lo que Lezama Lima propone como la "discontinuidad del bosque americano" , en tanto forma del tiempo de la dimensión que exige el señor barroco, en tanto templo y "fuscum subnigrum" de su manifestación; el señor barroco en tanto mónada abierta y sujeto excedido, en el rebasamiento ontológico que conlleva la praxis de la razón barroca, expone la "contra conquista" (Lezama, 
2005: 91) de sí, el otro, la naturaleza, el mundo; que provoca una moción barroca de la identidad, por precipitación de un caudal mnemónico compuesto por el espacio gnóstico del saber, en tanto era imaginaria frente a la historia y su representación.

De acuerdo a Lezama Lima, será en la manifestación de la indiátide, en la obra barroca del indio Kondori, que el barroco de alteridad del otro mundus imaginallis, tiene un punto de exposición; según Lezama, in extenso:

(...) el esfuerzo por alcanzar una forma unitiva, sufre una tensión, un impulso si no de verticalidad como en el gótico, si un impulso volcado hacia la forma en busca de la finalidad de su símbolo. En la Basílica del Rosario, en Puebla, donde puede sentirse muy a gusto ese señor barroco, todo el interior, tanto paredes como columnas es una chorrera de ornamentación sin tregua ni paréntesis espacial libre. Percibimos ahí también la existencia de una tensión, como si en medio de esa naturaleza que se regala, de esa absorción del bosque por la contenciosa piedra, de esa naturaleza que parece rebelarse y volver por sus fueros, el señor barroco quisiera poner un poco de orden pero sin rechazo, una imposible victoria donde todos los vencidos pudieran mantener las exigencias de su orgullo y de su despilfarro. Vemos que en añadidura de esa tensión hay un plutonismo que quema los fragmentos y los empuja, ya metamorfoseados hacia su final. En los preciosos trabajos del indio Kondori, en cuyo fuego originario tanto podrían encontrar el banal orgullo de los arquitectos contemporáneos, se observa la introducción de una temeridad, de un asombro: la indiátide. En la portada de San Lorenzo, de Potosí, en medio de los angelotes larvales, de las colgantes hojas de piedra, de las llaves que como galeras navegan por la piedra labrada, aparece suntuosa, hierática, una princesa incaica, con todos sus atributos de poderío y desdén. En un mundo teológico cerrado, con mucho aún del furor a lo divino tan medieval, aquella figura, aquella temeridad de la piedra obligada a escoger símbolos, ha hecho arder todos los elementos para que la princesa india pueda desfilar en el cortejo de las alabanzas y las reverencias (Lezama Lima, 2005:93-94).

El orden sin rechazo, propuesto por Lezama como forma de exposición del poderío del señor barroco, se relacionaría con la noción de "nueva armonía" propuesta por Deleuze (1989) que conlleva una armonía de la turbulencia, presente en la precipitación crepitante de la imagen que arde en los sentidos y que expone la erótica-crítica de la estética política barroca, cuyo desarrollo hermenéutico provoca la escultura viviente del pathos barroco como forma de exposición de una soberanía de alteridad; de ahí que, según Juan Duchesne Winter (2008): "Oppiano Licario, y el propio José Cemí constituyen advocaciones del señorío barroco en Paradiso. Si bien poseen rasgos y gradaciones distintivos, contribuyen a perfilar una singular figura de la soberanía con interesantes implicaciones poético políticas." - Lo que conlleva en la esferaimagen de la presentación del pensar barroco, su obra, la vivencia erótica de una relación con el cosmos, el mundo, la naturaleza, los otros en -: "un espacio geopoético: el reino americano del cual Cuba aparece como la sinécdoque insular, como el fragmento alegórico que conduce al claroscuro universo de lo cognoscible y lo incognoscible" - Cuestión que expresa la equivocidad que entre cielo y tierra, expone el espacio tiempo geopoético de lo insular en donde lo telúrico y lo celeste, componen las relaciones heurísticas entre lo que se conoce y lo desconocido, lo visible y lo invisible, lo legible y la 
ilegibilidad del logos plural que permite el discurrir del decir barroco, a través de la formalización heteromórfica de la gramática de la turbulencia como praxis discursiva asignificante, lo que implica una política incomunista ${ }^{7}$ de la comunicación poética ${ }^{8}$ propulsada por la soberanía del sentido/sensación de las voces barrocas, de ahí que - "Su señorío de dicho espacio se da en la forma de un doble movimiento sensorial e imaginario, que conlleva un descenso órfico hacia el conocimiento de las cosas y un ascenso creativo hacia las imágenes de las cosas, que adquieren su propio cuerpo y consistencia, su verdad, dentro de un telos alegórico trascendente" (Duchesne Winter, 2008: 22). Turbulencia paradójica de la armonía de alteridad que se pone en escena con el mundus imaginallis otro en la puesta en abismo equivoca con el "telos alegórico trascendente" de la inversión categórica del des-

7. Para la noción de incomunismo, como apertura política ante el consenso del multiculturalismo como forma de régimen de representación de la noción de comunidad fundada en la identidad como clausura ontológica, ética, poética, estética, política, ver: "Fugas incomunistas". Juan Duchesne Winter. Puerto Rico, 2008.

8. En relación a una comunicación barroca, se propone tener en cuenta la siguiente mención: "El señor lezamiano, principalmente en su advocación de poeta (que no es la única), constata en un principio lo que él percibe como "el enemigo rumor" de las cosas, entre ellas las palabras y la propia poesía. Es decir, detecta en ellas una positividad propia perturbadora, pero no pretende poseerlas ni negarlas, sino comunicarse con ellas. Se encamina indefectiblemente hacia ellas para vencer su propia alienación (su "fragmentación", su "ausencia" o "lejanía" en el lenguaje del poeta), y las acomete con sutil voluntad metafórica, reinventándolas como imagen, como artificio de "sobrenaturaleza". Se trata de una aproximación que respeta la corporeidad de la imagen poética, tan soberana en su sustancialidad propia, que se le presenta como "enemiga" que incita comunicación" (Duchesne Winter, 2008: 34-35). Mociones de sentido que se relacionan aquí con la comunicación de alteridad en una dialógica entre la desarticulación continua de la lengua, que provoca la "nueva armonía" de la gramática de la turbulencia y lo que se podría referir a una esquizoanalítica del logos plural del pensar barroco, que in-comunica por el despliegue de sentidos/sensaciones del decir como perla irregular y esferaimagen del acontecer. censo órfico, como forma de exposición de una anamnesis de alteridad barroca; en el caso de la geopoética insular de Lezama provocada por Eshú, Dios de las encrucijadas y las esquinas quien provoca relaciones con lo Santo y en el caso de la "temeridad" del "plutonismo" del indio Kondori, en el Duende, provocador del entunde como forma de relación con lo trascendente inmediato, Dios de las encrucijadas o quingos ${ }^{9}$, en donde se entrelazan y trenzan las relaciones del sentido/sensación multinaturales del discontinuo logos plural del pensar político barroco y la exposición de una soberanía alterada (de alteridad). De ahí que: Lezama no habla de "señor" barroco por nada. Pudiera haber dicho, "sujeto", "personaje", u "hombre" barroco, pero insiste en designar el señorío, una soberanía personal, que si bien se articula sobre el espacio geopoético que hemos descrito, invocando un dominio de la experiencia ética y estética en lugar del poder en su sentido ordinario, no deja de implicar lo político, como lo hace todo señorío o soberanía. No olvidemos que

9. Quingo: de "Kinku: Adj. Zig-zag, curva, sinuosidad". En: Diccionario Kichwa Yachakukkunapa Shimiyuk Kamu. Kichwa - Castellano. Ministerio de Educación del Ecuador. 2009. Página 81. En el imaginario amerindio, estas sinuosidades se observan en los cruces de caminos que se trazan en las montañas y que se hacen en zig.zag. En cada cruce, en cada vértice que compone los cruces que componen el camino, se suele hacer pagamentos, consistentes en ofrendas en algunos puntos del camino en donde se ubican Apus, consistentes en montículos de piedra que señalan lugares huaca, es decir espacios y tiempos de encuentro con espíritus, a quienes se ofrenda tabaco u hojas de coca, con saludos y oraciones, para que acompañen en el camino o lo despejen de cualquier malestar. Los Kingos además se relacionan con la Hullahuanga o urdimbre que se utiliza para entretejer la trama de un texto posible de expresarse en un chumbe o faja que suele utilizarse para fajar a los recién nacidos, pero que también utilizan los chamanes para cerrar el cuerpo en el momento de hacer una curación a otro, cierre que es una apertura en la que el chumbe en el que están trazados los kingos abre simbólicamente el cuerpo del chamán, quien acoge la dolencia, enfermedad o malestar del otro, y lo entreteje o teje de nuevo, armonizando otra vez el cuerpo del afectado. 
la palabra "señor" se define en oposición a "siervo" o "esclavo". Es señor quien no sirve a nadie, es decir, el sujeto soberano; por lo que la mera mención del señorío connota una dinámica intersubjetiva y colectiva de articulación de fuerzas y posiciones, es decir ineludiblemente política (Ibíd., 25).

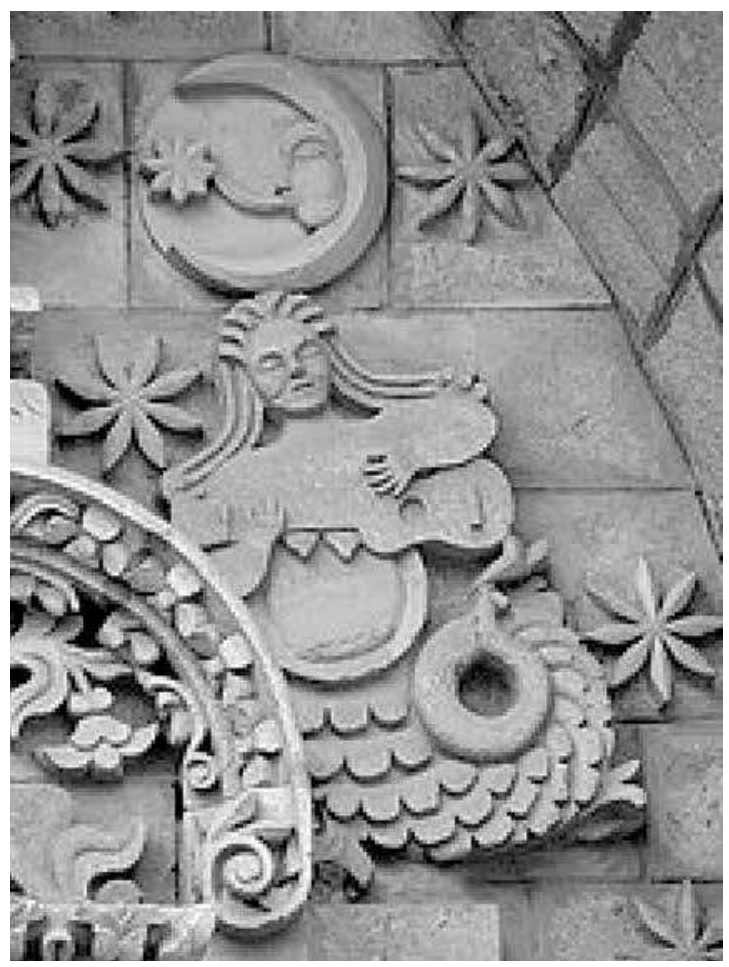

Figura 3

La soberanía de alteridad, de entunde, en el caso del señorío barroco está atravesada por la presencia del Santo, en este caso Eshú, lo que provoca una remoción ontológica que permite la excedencia que el señorío expone, y que promueve además una política de alteridad que establece relaciones con lo que Santo, despliega nuevas armonías, inflexivas, asignificantes, turbulentas, disentivas por saturación de sentido/sensación. En el caso de la Santidad Americana, de la relación de entunde, con el Duende, se podría encontrar la exposición de esa temeridad de la indiátide en la propuesta sobre la estética americana que según Kush conlleva pensar que:

El problema del arte en América Latina es el problema de su vida política, social y económica. Se trata de la misma alternancia amarga entre luz y sombra, la misma reversión de lo que nos parece real y firme y nos infunde placer. Detrás del formalismo elegante de Mitre la fealdad heroica del Martín Fierro. El arte americano es dual, bifronte con dos caras, que mantienen entre sí un abismo similar a la oposición maldita entre Dios y el Diablo. (...) El miedo de vivir lo paraliza todo y, más aún, el miedo de vivir lo americano. (...) Así toda situación social, política, cultural artística tiende a asesinar a la inferior y se hace arte urbano matando al rural, como también se hace arte rural matando al ciudadano. El arte surge así de un miedo original que cuestiona a lo amorfo su falta de forma. La visión que un artista corriente tiene de lo americano, contiene esa irritación por la ausencia de equilibrio formal. Se refugia de inmediato en esa predisposición colectiva al estrato, a lo formal, a lo estable, llevado por una especie de pánico de que lo que está abajo pudiera destruir lo de arriba. $Y$ en el caso de rozar algo muy hondo, que penetre en lo americano, el artista o el escritor tienden sobre esa hondura un barroco conceptual sutilmente entretejido para cerrar toda posibilidad de visión o de resquicio hacia lo viviente" (Kush, 2000: 779-781).

Tal cierre conllevaría la "clausura" necesaria subrayada por Deleuze, en relación a la dinámica del barroco y que se puede proponer como una forma de exposición dehiscente, más como velo y límite, himen "barroco conceptual sutilmente entretejido", que como cierre 
total; debido a que en el caso del barroco americano se trataría de una mónada en fisión, es decir abierta al afuera de las relaciones que excede por lo pánico de su acción, el barroco tendría un modo de presentación pánico, referido al "fuscum subnigrum" como templum paradójico que invierte la perspectiva ${ }^{10} \mathrm{y}$ altera el cosmos, la naturaleza, el mundo, los otros por la discontinuidad pánica de la relación crítica.

El tiempo de dicha discontinuidad, implicaría por tanto una coordenada intensiva de las fuerzas plásticas de la manifestación del ser-barroco, que complicarían la reducción ontológica de la presencia del ser para sí, y la clausura en la que lo somete; debido a la heterarquía $^{11}$ de la ontología plural de la manifestación barroca de su presentación, de su manifestarse discontinuo, por tanto tangente y oblicuo, en tanto exposiciones de una meta e hiper física barroca, que implicaría la pluralidad de lo originario por la precipitación de la multiplicidad de sentidos y formas de la heteroestesia del logos barroco.

El pensar sin modo, su "punto de vista" (Deleuze, 1989), implicaría en esta instancia meta-lógica un ethos pluralizado cuyos tiempos de exposición manifestarían un ser inacabado por lo forma anómala de su presentación, que de acuerdo a la comprensión del ser barroco que propone Deleuze, se pliega y repliega en el caudal de devenires que lo transvierten como extraser.

10. La inversión perspectiva es referida por Deleuze en: "El pliegue. Leibniz y el barroco". Paidós. 1989. La noción de inversión perspectiva se puede ampliar a partir del trabajo de Pavel Florensky. Ver: "Beyond Vision. Essays on the perception of Art." Edited by Nicoletta Misler. 2002. Reakton Books. London.

11. Heterarquía es una noción propuesta para pensar las relaciones de disenso a partir de una comprensión del diferendo en la constitución de la noción de democracia, desarrollada por Kyriakos Kontopoulos, en "The logics of social structure" 1993. London. Routeledge.

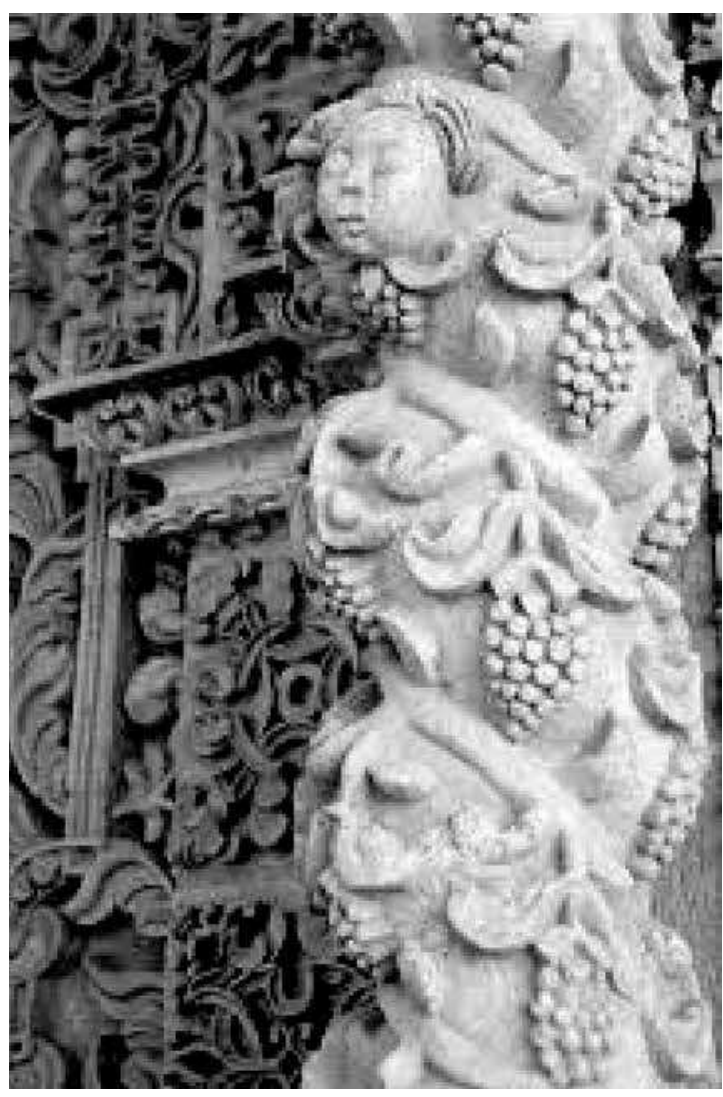

Figura 4

Según Deleuze:

Los puntos de vista son un segundo tipo de singularidades en el espacio, y constituyen envolturas según relaciones indivisibles de distancia. Pero ni unos ni otros contradicen el continuo: hay tantos puntos de vista, cuya distancia es cada vez indivisible, como inflexiones en la inflexión, cuya longitud es cada vez mayor. El continuo está hecho de distancias entre puntos de vista, no menos que de la longitud de una infinidad de curvas correspondientes. El perspectivismo es realmente un pluralismo, pero como tal implica la distancia y no la discontinuidad (Deleuze, 1989: 32).

Tal mirada oblicua como refiere Lezama Lima, permitiría entrever la discontinuidad de la presencia y esta- 
blecer una relación con lo invisible, en tanto el perspectivismo barroco conlleva la praxis de una razón saturada, es decir de un logos-sentido-sentiente-desensación, referido a una erótica política de la estética de la razón plural como posibilidad de comprensión de la representación barroca de la estética de alteridad americana, que permitiría cimentar la base para una hermenéutica dirigida a la exposición de: a) una Antropología filosófica barroca, ocupada de las relaciones de alteridad en una comunidad plural, b) La filiación barroca, dirigida a la comprensión de la política de alteridad del excedente ontológico que conlleva el señor barroco, c) el Eros del conocimiento y la lejanía, como dimensiones epistémicas de alteridad capaz de establecer relaciones de saber y poder con un "telos alegórico trascendente" como instancia en la que confluyen plurales puntos de vista, tendientes a la composición de una política perspectivista, d) La diferencia barroca, como forma de expresión de una política del disenso, capaz de asumir la excedencia ontológica, a partir de una comprensión fenomenológica e hiperfísica del cuerpo, los sentidos/las sensaciones de la relación insular, telúrica, volcánica, celeste, Santa, animal, humana, no humana, con otro.

Imágenes: Figura 1, 2, 3, 4. Fachada de la iglesia de San Lorenzo. Potosí.

Fuente: Google. JoséKondoriimagenes. Recuperadas: Mayo 30 de 2013. 11:50 a.m. 


\section{BIBLIOGRAFÍA}

Agamben, Giorgio (2010). Ninfas. Pre-textos. Valencia. Traducción de Antonio Gimeno Cuspinera.

Cabrera, Lidia (1968). El monte. Igbo. Finda. Ewe Orisha. Vititi Nfinda. (Notas sobre las religiones, la magia, las supersticiones y el folklore de los negros criollos y del pueblo de (uba). Rema Press. Miami Florida.

Deleuze, Gilles (1989). El pliegue. Leibniz y el Barroco. Paidós Ibérica. Barcelona. Traducción de José Vásquez y Umbelina Larraceleta.

Didi-Huberman, George (2007). La pintura encarnada. Seguido de "la obra Maestra desconocida. Honoré de Balzac". Pre-textos. Valencia. Traducción de Manuel Arranz.

Duchesne Winter, Juan (2008). Del príncipe moderno al señor barroco: la república de la amistad en Paradiso, de José Lezama Lima. Fundación editorial archivos del Índice. Cali.

(2005). Fugas incomunistas. Ediciones Vértigo. San Juan de Puerto Rico.

Escobar, Arturo; OSTERWEIL, Michael (2009). Movimientos Sociales y la Política de lo Virtual. Estrategias Deleuzianas. En: Tabula Rasa. No 10. Enero-Junio. 2009. Bogotá. Páginas: 123-161.

Florensky, Pavel (2002). Beyond Vision. Essays on the perception of Art. Edited by Nicoletta Misler. Reakton Books. London.

Grosso, José Luis (2013). Oblivion saves other histories in bodies. Post-colonial semiopraxis, denegation politics, and cultural learnings. En: VIII Symposium CORPUS Bodily cultivation \& cultural learning. Thematic Area: Memory and Body. Taipei, May 25, 26. Paper.

Kontopoulos, Kyriakos (1993). "The logics of social structure". London. Routeledge.

Kush, Rodolfo (2000). Pozo de América. En: Obras completas. Volumen I. Editorial Fundación Ross. Provincia de Santa Fe. Argentina.

Lezama Lima, José (1979). Esferaimagen. Sierpe de Don Luis de Góngora. Las imágenes Posibles. Tusquets editores. Barcelona.

Lezama Lima, José (2005). La expresión americana. Fondo de Cultura Económica. México.

Lezama Lima, José (1971). Introducción a los vasos órficos. Barral Editores. Barcelona.

Madroñero Morillo, Mario (2012). Antropologías de lo inaparente. Saberes ausentes, epistemologías invisibles. En: Ciberalfaro. Texto Académico de Investigación y Creación. No 24. Revista de la Universidad Laica Eloy Alfaro. Editorial Mar Abierto. Manabí. Ecuador. Páginas: 51 - 68.

Madroñero Morillo, Mario (2012). Multinaturalismo y Estéticas de alteridad. En: Calle 14. Revista de investigaciones en el campo del arte. Facultad de Artes de la Universidad Distrital. Volumen 6 No. 8. Corte EneroJunio. Bogotá, pp. 102-119.

Ministerio de Educación del Ecuador (2009). Diccionario Kichwa Yachakukkunapa Shimiyuk Kamu. KichwaCastellano. Ecuador.

Viveiros de Castro, Eduardo (2010). Metafísicas caníbales. Líneas de antropología postestructural. Katz editores. Buenos Aires. Traducción de Stella Mastrangelo. 